Erratum

\title{
Erratum: Liu, W.; Ban, J.; Feng, L.; Cheng, T.; Emmert-Streib, F.; Dehmer, M. The Maximum Hosoya Index of Unicyclic Graphs with Diameter at Most Four. Symmetry 2019, 11, 1034
}

\author{
Weijun Liu ${ }^{1}$, Jingwen Ban ${ }^{1}$, Lihua Feng ${ }^{1}$, Tao Cheng ${ }^{2}$, Frank Emmert-Streib ${ }^{3}$ and \\ Matthias Dehmer $4,5,6, *$ \\ 1 School of Mathematics and Statistics, Central South University New Campus, Changsha 410083, China \\ School of Mathematics and Statistics, Shandong Normal University, Jinan 250014, China \\ 3 Predictive Society and Data Analytics Lab Faculty of Information Technolgy and Communication Sciences, \\ Tampere University, 33100 Tampere, Finland \\ 4 Department of Biomedical Computer Science and Mechatronics UMIT, 6060 Hall in Tyrol, Austria \\ 5 College of Articial Intelligence, Nankai University, Tianjin 300350, China \\ 6 Swiss Distance University of Applied Sciences, 3900 Brig, Switzerland \\ * Correspondence: matthias.dehmer@umit.at
}

The authors wish to make the following corrections to their paper [1]:

The FWF project number in the funding section should be P 30031.

The authors would like to apologize for any inconvenience caused to the readers by these changes. The changes do not affect the scientific results. The manuscript will be updated, and the original will remain online on the article webpage, with a reference to this correction.

\section{Reference}

1. Liu, W.; Ban, J.; Feng, L.; Cheng, T.; Emmert-Streib, F.; Dehmer, M. The Maximum Hosoya Index of Unicyclic Graphs with Diameter at Most Four. Symmetry 2019, 11, 1034. [CrossRef]

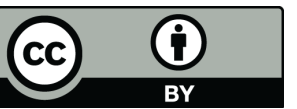

(C) 2020 by the authors. Licensee MDPI, Basel, Switzerland. This article is an open access article distributed under the terms and conditions of the Creative Commons Attribution (CC BY) license (http://creativecommons.org/licenses/by/4.0/). 